\title{
The Bottleneck and Breakthrough Path of Vocational College Counselors' Professional Development in the Perspective of Psychological Contract
}

\author{
Mingyan Zhang \\ School of accounting and Finance, Wuxi Institute of Commerce, Wuxi, Jiangsu, 214153 \\ zhangmingyan@wxic.edu.cn
}

Keywords: Psychological contract; Vocational colleges; Counsellors; Professional development

\begin{abstract}
Counselors are students work in higher vocational colleges mainly responsible for, for a long time, higher vocational colleges on the counselor team development concern and attention is not enough, at present the counselors' professional development facing "team", "status is not high", "job responsibilities is not clear," and other issues, the development path and the knowledge and skills of construction faces a dilemma. Based on psychological contract perspective, in light of the difficulties encountered in the development of the professionalization of instructors, scientific design incentive system and career development ladder, the establishment of counselor certification system and practice access system, build a platform for the development of the "double teacher type", through the construction of psychological contract of interaction mode crack the counselors' professional development bottleneck, the implementation of psychological contract incentives and shaping a good team culture to promote counselor professional development.
\end{abstract}

\section{Introduction}

With the continuous development of China's economy and society and higher education, and the importance of the ideological and political education is becoming more and more clear, and the professionalization of the college counselors team has become the inner demand and the demand of the times. Counselors are the main bearer of the students' work in Higher Vocational colleges, for a long time, higher vocational college's concern and attention on the counselor team development are not enough. In the process of professional development, counselors are faced with problems such as "unstable team", "low status" and "unclear job responsibilities", at the same time, in the development path, facing the dilemma of administrative duties and professional and technical positions, facing the broad or profound dilemma in the construction of knowledge and skills. Research on the problems faced by counselors on the professional development has important significance to promote the smooth development of professional counselors and improve counselors' career satisfaction, establish good counselor's professional emotion and stability of counselors in vocational colleges.

\section{The Bottleneck of Vocational College Counselors' Professional Development}

"Employment Oriented" Higher Vocational Education Has Increased the Difficulty of the Work of Counselors. Ministry of Education pointed out that the higher vocational education must be guided by employment, and puts forward new requirements for the work difficulty of the instructors in "on the employment oriented, deepening the reform of higher vocational education opinions". The current employment situation is grim and college students' employment pressure is too large. If higher vocational students want to find a satisfactory job, as a counselor, he must give students enough guidance in the student employment, job, psychological and other aspects to, so that they can go to work and be able to face.

Irrational Counselor Team Structure Impacts of Vocational College Counselors Professional Development. Counselors' professional background is becoming more and more diversified, professional configuration is not reasonable enough, which may become the restricting 
influence factors [1]. At present, some vocational colleges fail to comply with the rule of the Ministry of education with a scale 1:200. The scale of the instructor team cannot meet the needs of students, and it has a direct impact on the effect of the work. Counselor team structure is irrational, mainly in the age, gender, professional and academic title structure. The average age of the counselor team is too small, social experience is relatively insufficient, work experience and other parties are not enough, so that they cannot give a good guide in many problems. Female counselors are more than male instructors a in the counselors, which has a lot of inconvenience For the students to carry out the activities of the most direct, students to manage the routine work, such as dormitory management; Instructors with the ideological and political education, psychology, education and sociology and other related professional background are less, so they is not good to undertake the task of education, guidance and service for students. Counselors obtained psychologist and other qualification certificate are very few; Counselors with a high degree, high title, ready to work for a long time in the work of students and strive to become experts in this area are few; Student's research aspect is not wide and the research is not deep, which to a certain extent, influent the construction of the counselor team and the innovation of student work.

Great Mobility Affects the Stability of Higher Vocational College Counselors Team. Some of the counselors to be engaged in counselors work are lack of mental preparation. Most people think there is no future for the work of counselors and actively seek reorientation. When a group of counselors are mature, they will go away. With higher vocational colleges to develop the connotation, the counselor team is still not stable enough. Because a number of counselors are College graduates who participate in the work in recent years, most of them have their own professional, as the current severe employment situation, they have to choose to engage in the work of Counselors. This for them is just a temporary expedient, but for higher vocational education management system is lack of a clear ideas, long-term planning and clear target. Counselor's work is not continuous, fault, low professional level. Students' Ideological and political education work only in the maintenance of the management, lacks of integrity, continuity, innovation.

Organizational Affiliation and Lower Treatment Restricted the Work's Enthusiasm of the Higher Vocational College Counselors. Counselors as a special group of higher vocational colleges are in charge of all. Organization Department, propaganda department, student work apartment, the Youth League Communist and the location of secondary school, a number of work, multiple management, multiple assessment, lead that counselors are no sense of belonging and accomplishment, Job responsibilities are not clear, things are too many and strong, so that General feel confused of the future. The treatment of counselors is generally low, the post allowance standard of higher vocational college counselors is single, there is no grade gap, and is not closely linked to the counselors work performance, which restricts the works enthusiasm of Counselors. The career development of the counselor team is not clear, the job responsibilities are not clear, professional is not prominent, so it cannot really realize the professional development of their own [2]

The Work Responsibility Is Big, the Business Is Complex, Causing the Counselor to Have the Occupation Anxiety. Counselors work is the first line of Ideological and political education of college students, is a direct responsible person". With the popularization of higher education, increasing number of students, 95's generation becomes the main, part 95'sgeneration students with vulnerable psychological, poor self-care ability, weak awareness of self-discipline. Foreseen and unforeseen contradictions and problems are endless and the instructor may need to arrive at the scene to deal with. Counselors' work relates to the student's every aspects, including security and stability, student party building, the construction of style of study, social practice, dormitory management, students' psychological health education, employment guidance, poor students reminders and tuition fees, and so on, complicated matters. Because the pressure is too large, work is too tiring, a lot of counselors are affected by the physical health; because of the work of the transaction, the fast pace of life, instructors cannot devote themselves to learn and study. With the great responsibility of the work, the counselors will cause occupational anxiety, and affect the ability of the business. 
Lower Occupational Reputation Seriously Affects the Continuity of the Work of Counselors. The Higher Vocational Colleges counselor's occupation prestige is lower than undergraduate college counselors and full-time teachers in Higher Vocational Colleges. Because the university is to train specialized personnel, is the position of academic research and teaching reform and innovation, the treatment of professional teachers, academic personnel in material and spiritual aspects is superior. many counselors have no place in the teacher, have no prestige among the students because of the lack of academic specialization, plus the social prejudice to the instructor's career, which makes some counselors have a significant difference on psychological, affects the identity of the counselors and professional feelings [3]. The heavy use and light training of instructors in Higher Vocational colleges, lack of counselor team building planning and effective measures. The Counselor's learning opportunities are less, the counselor team construction funds also exist relatively insufficient, so that the instructor's own work cannot be further developed. Counselor every day busy student management work and deal with a large amount of tedious affairs, lack of professional ideal. Economic gap and work pressure, resulting in the most ideological instability, most counselors eager to turn full-time teachers, to find a way to leave a counselor, seriously affect the continuity of Counselor's work.

\section{Countermeasures to Break the Bottleneck of Vocational College Counselors' Professional Development}

Reform of the Current System Is the Prerequisite for the Realization of the Counselor's Professional Development. Firstly, a system, new management model should be formed for counselors. Counselor to implement management by objectives, break the previous sitting office-hour system ,enables the counselors to have a reasonable arrangement and adjust the time, fully mobilize their autonomy and enthusiasm, to ensure that it has enough time and effort into self-ascension. At the same time to make up multi training instructors of "Two Courses" platform, become the teacher of Ideological and political education. Less counselors are multiple levels of management, but also reduces the amount of work, the counselor from multiple management and transactional work to be liberated, making the work of counselors more productive.

Secondly, improve the treatment of, and stabilize its economic status and academic status. Counselor's work tasks, demanding, high pressure, dedication and more, if you do not solve the problem of treatment, it will inevitably appear psychological imbalance, impacting of the stability of the counselor team and work. To establish a set of perfect training mechanism, such as training teaching and academic backbone, so as to cultivate high level and high quality students' Ideological and political work.

Thirdly, establish and improve the incentive and security mechanism of the counselor team. Considering difficulty of counselor work, appropriate in terms of post allowance, work reward, working conditions and other are given to tilt, as they solve problems, so as to stabilize the counselor team. Through counselors vocational skills competition, establish special appraising reward system, regular assessments in recognition of outstanding counselor and a series of activities, play an exemplary role model of outstanding counselors, counselors lead constantly upgrade themselves.

To Strengthen the Development Guidance of the Counselor Team, so as to Avoid the Development of Spontaneity and Blindness. The one is to establish the concept of professional development, as soon as possible to determine their own career anchors. The two is to correctly understand the pressure and contradictions in the professional development of, the correct understanding of the positive significance of occupational stress, and constantly improve their ability to resist pressure and frustration, improve their psychological quality. The three is to improve their qualities. Counselors should continue to improve the knowledge and practical ability, and actively carry out research and write papers related to higher vocational education, to prepare for lifelong career education. The four is College Counselor's professional development, higher vocational colleges in the selection of appointment management cadres of the party and government should be adhere to outstanding counselors from the selection, improve instructors' work 
enthusiasm and persistence, for the instructor to create more relaxed development space and more favorable conditions for the development .

Strengthen the Training, Enhance the Ability of the Sustainable Development of Counselors. On the one hand, schools should introduce preferential policies, combine the use and cultivation, actively encourage counselors to continue their studies, studying for the education, management science, psychology and other disciplines for master's degree, in learning improve theoretical level, focusing on the cultivation of students work in teams on the backbone of business, enhance the ability of counselors, promote the sustainable development of College Counselors.

On the other hand, schools should regularly organize counselors, by full-time education or special training to improve the counselors in Ideological and political education, psychology, legal security, management ability, employment guidance level of knowledge and skills. Selecting outstanding counselors to undergraduate colleges and universities to take exercise, enhance ability of Vocational College Counselors deal with various unexpected events.

The third is to establish the daily training, vocational training and professional training in the combination of multi-level, multi form of systematic training system. Stick to the combination of daily training and professional training, theory and business training, pre job and on-the-job training, full-time or part-time training and on-the-job training, on campus and off campus training, academic training and non academic training, professional training and mental training. In a variety of training, it can broaden the vision of counselors, broaden the counselors' ideas, improve the ability of counselors to solve practical problems.

The Four is to focus on improving the quality of education and the level of ability based on the actual needs of the future needs to strengthen the training of counselors. Through establishing counselor training files, rich training content, to broaden the training channels, etc., take grade progressive training and counselor qualification training to the level of combination, and lay a solid foundation for better service to the student's growth and success.

Optimizing the Structure of the Instructor Team and Improving the Overall Quality of the Counselor Team. Higher vocational colleges should be in accordance with the requirements of "the provisions for the counselor team construction of ordinary colleges and Universities" implement the preparation of counselors, strict appointment of the standard in full, optimize the existing structure of the instructor team, from the number of structural requirements, According to the orientation, characteristics and their occupation education in the direction of running a school, school characteristics, on the construction of the counselor team planning, the construction of the counselor team included in the school teacher training plan and personnel training program. Overall planning and unified leadership. According to the reality of school development gradually, solve their rank and status, and fully mobilize the enthusiasm of instructors' work and create, from the change of students' education and management mode for counselors "burden", from the evaluation mechanism improve Counselor's reputation, the flow mechanism implementation auxiliary guide member "excellent" virtuous circle.

\section{Breakthrough Path of Vocational College Counselors' Professional Development}

At present, higher vocational colleges from scale development to connotation construction, education system, mechanism of management, talent training mode have undergone profound changes; psychological contract violation is counselors in higher vocational college's employment relationship of a kind of emotional evaluation and cognition. Under the new normal, both the counselors and the vocational colleges are more difficult to define and fulfill the responsibilities, and further strengthen the possibility of psychological contract violation. The basic way out for the construction of the counselor team in higher vocational colleges is to carry out professional construction, scientific design incentive system and career development ladder, the establishment of counselor qualification certification system and practice access system are to build a "double division" development platform. Through constructing the interactive mode of psychological contract to break the bottleneck of the professional development of counselors, implement psychological contract incentive and create a good team culture to promote the professional 
development of counselors, improve the efficiency of education and management of students, and further optimize the whole student education management system.

Scientific Design Incentive System and Career Development Ladder. The professionalization of the work of a counselor can be put the first hand information and valuable experience of the instructor into second, third or more cycles of work, which avoids the beginning of the exploration, so that the accumulation of valuable experience in the work of students get the most fully re use, maintain the sustainable development of the work of counselors, thus making the work more effective. Through a set of standardized, scientific, institutionalized counselor assessment and training mechanism, guide counselor team dedication to achieve instructors strict requirements, strict management and promote counselors work on professional road. In the construction of the professionalization of the counselor team, the analysis and positioning of each instructor, help them establish their own professional goals, goal posts and ranks in the target in 3-5 years of development track, making it clear in the school development in different stages of personal positioning and the corresponding task. Guide the counselors in the specified time to complete the expected career goals, give guidance and training, and continuously improve the professional skills and management of Counselors. At the same time, also optimize the performance evaluation and incentive mechanism, implement the security measures to eliminate the worries of the development of counselors, so as to enable the work of counselors to work as a long-term career. According to giving full scope to the talents of the principle to design an incentive system and career development ladder, Use various effective incentives to stimulate the sense of responsibility, sense of belonging and work enthusiasm, and constantly develop and maintain the psychological contract of the counselors, to improve the enthusiasm and creativity of the counselors [4].

Establish the System of Qualification Certification for Counselors and the System of Practicing admittance. It is an international practice to establish a professional access system and a professional qualification certification system in a specific field. existing qualification requirements is set according to the post in Higher Vocational Colleges, the different positions with different eligibility requirements, included in the series of dual control over teachers and administrators counselors, according to the requirements of teachers' post series, the basic qualification requirements and teacher the same. It should be see that the counselor is an important part of teachers, but counselors is not a teacher in general sense, vocational theory teaching posts, practice teaching posts, counselor the responsibilities, each other can not be replaced. In comparison, a counselor for practitioners has the basic requirements of higher quality, knowledge required more comprehensive and found the problem, analysis problem, stronger problem-solving ability, more broad Counselor's work in the field, the responsibility of educating more prominent. Starting from the objective of optimizing the structure and establishing a contingent of highly qualified instructors, analysis from the level of professional counselors, a counselors qualification certification and licensing system should be established as soon as possible. Practice access system establishes a platform on the import to restrict improper personnel into the team of counselors and ensure the overall level of the instructor team. Certification can be from the professional level set counselor job responsibilities and quality requirements and business level, in accordance with the provisions of the program for teachers, educational administrators in professional title evaluation, to establish the counselor certification and professional title evaluation system.

Build a "Double Division" Development Platform, and Guide the Counselors to Take the Road of Professional Development. Higher Vocational College "double teacher type" counselor system refers to the instructor should not only be the traditional sense of political teachers", at the same time it should be a specialist in the field of work, such as counselors, occupation guidance etc. Higher vocational colleges should provide professional planning for the instructor, design science instructor team professional development line, as counselors in the business of learning, research, education and participation in scientific research, also should remove obstacles, to build a platform, the creation mechanism. According to the rank of professional teachers, establish corresponding full-time counselors rank system etc. On the implementation of the employment system, the training of "double division" of the instructor team can also achieve two-way flow inside and outside the 
school, the formation of open, overpass bridge construction mode. Vocational college counselors should base on that strengthen the professional ethics, strengthen the ideological and political quality, promote the spirit of professionalism, Efforts to adapt to the needs of the work and the times, "the strong quality, outside the plastic image", and students in the same knowledge platform to grow, Vying for learning counselor, to achieve the traditional political type, transaction type to the type of scholar type, career change, to the performance and achievements to establish its rightful place.

Construct a Psychological Contract Interaction Mode between Higher Vocational College and University Counselors. The higher vocational colleges should avoid making "over commitment" in the management of counselors, fully consider the psychological contract between the personal development of the counselors and the post formation of Vocational colleges, to provide a platform for the development of the carrier and the career of the counselors, the counselors have a deep sense of identity to the University's culture and system, and it is helpful to the psychological contract of both sides in a positive interactive mode [5]. With the understanding of the roles and responsibilities of the counselors in the psychological contract being more and more accurate, vocational college counselor professional development should be focused on enhancing Counselor's professional attraction, focus on the establishment of humanistic campus culture, for between Higher Vocational Colleges and counselors keep common psychological contract, to create a good working atmosphere, achieve the benign interaction between Counselors and campus culture in Higher Vocational Colleges.

By enhancing the sense of career and achievement of the counselors' work, establishing the career ideal of the counselors, constructing the life value realization mode of the instructor's career, combine realization of the self-value of counselors with the strategic development of Higher Vocational Colleges to achieve a dynamic balance between personal development and the goal of Higher Vocational colleges. Gradually get rid of the current way is to encourage counselors to switch a job, gradually improve the encouragement of counselors "job success", "post development", "post dedication", to establish a series of long-term mechanism for the assessment, rewards and punishment, promotion, and strengthen the Vocational College Students' Ideological and political work.

\section{References}

[1] $\mathrm{Hu}$ xinyan. Research on career path of college counselors [J].School party building and ideological education. 2014 (1):77-78

[2] Zhang Xiaoming, Qiu Fengxing. The bottleneck of the professional development of college counselors and the breakthrough path [J].College counselors, 2012 (6):76-79

[3] Ma Lin, Ren Min. An analysis of the professionalization of counselors in the perspective of occupational commitment [J]Education and teaching research, 2010 (9) 33-35

[4] Li Zongbo, Li Qiaoling, Tian Yanhui. Influence mechanism of job involvement on emotional exhaustion -- Research on job demand resource model [J]. soft science, 2013 (6): 53-61

[5] Duan Xinxing, Yang Kang. Research on the professional development of counselors from the perspective of psychological contract [J]. Jiangsu higher education research, 2013 (1):81-84 